\title{
FROM SOCIAL RESPONSIBILITY TO SOCIAL MEDIA RESPONSIBILITY: RECOMMENDATIONS FOR INTEGRATING SOCIAL MEDIA INTO ORGANIZATIONS
}

\author{
Emad Bataineh and Zakaria Maamar \\ Zayed University, Dubai UAE
}

\begin{abstract}
Social media can be defined as any form of interactivity, whether online or offline, that arises over dedicated Web- and/or mobile-based platforms and involves individuals and/or organizations. Interactivity could be about any topic ranging from what to wear for a particular function to where to have dinner and when to launch a marketing campaign. Indeed, there is a growing interest in how organizations should capitalize on social media such as social networks, blogs, and wikis. A social organization is the one that strives to open-up new communication channels with stakeholders using social media. We all have been caught by social-media fever. There are 2.25 billion active users on Facebook; 58 million, average number of tweets per day; and 55 million photos uploaded every day through Instagram. This research paper presents a guiding framework to help governments ensure a proper integration of social media technology in its day to day operations and efficient use of social media by their employees. The framework stresses out 5 aspects referred to as technology, structure, and management.
\end{abstract}

\section{KEYWORDS}

Social Media, Web 2.0, e-Citizen

\section{INTRODUCTION}

The information and communication technologies (ICT) has changed the way people live, work, study, and communicate, one of these changes how citizens interact with their governments through social media applications. Social media can be defined as any Web or mobile based platform that enables an individual or organization to communicate interactively and to exchange user generated content. It's an open dialogue for communication between two parties. Online two-way form of sharing information, ideas, etc. often nicknamed "Web 2.0". Social media tools vary in their domains, purpose, approaches and their functionalities. Increasingly more accessible due to smartphones and internet connectivity. Users are now referred to as prosumers, i.e., providers and consumers at the same time.

Unlike conventional media e.g. radio, book, newspaper, TV, social media tools depend heavily on user-generated content which is created, shared, edited, by the public (Porter, 2008). Social computing is about collective action, content sharing, and information dissemination at large. Through it, users have the ability to interact, share, collaborate, generate and recommend content, people, applications, etc. Users of social media tools are now referred to as prosumers, i.e., providers and consumers at the same time. Social media tools were designed to provide a many-to-many social interaction environment, where as traditional media is primarily designed to be one-to-many platform. Social media technologies allow users to build online communities who have a common interest where members can interact with each other (Boyd \& Ellison 2007). Those communities provide users with web-based platform to exchange, share, view, discuss and store digital content in a virtual and social environment. The integration of social media tools has provided an open channel for government to interact with the members of the public and address their interests and concerns regarding government services. The integration has resulted in a fast and convenient $24 / 7$ access to information and services. The world has moved from traditional governments to electronic governments, mobile government, and currently to digital and smart government. 
One of the benefits of using social media in government, it increases access to government information and services. It also enhances transparency, democratic participation and public engagement with the decision-making process (Bertot et al. 2010). Though most e-government strategic initiatives are increasing their use of social media technologies to extend government services, keep an open channel of communication and reach out to the public (Bertot, Jaeger \& Grimes 2010). The citizens' right to access government information and services is considered by many international standards as an essential element to achieve democracy, transparency, accountability, public participation, trust and informed decision-making process (Reylea 2009 ; Mulgan 2007; Shuler, Jaeger \& Bertot 2010). According to "Transparency and Open Government, Memorandum for the Heads of Executive Departments and Agencies"(2009), the open government initiative of the US federal government encourage the implementation of three principles for a government: transparency, participation, and collaboration. Transparency can be achieved by keeping the citizens informed about what the government is doing; participation encourage public engagement and involving the public in policymaking; collaboration requires cooperation among government agencies, businesses and individual citizens to enhance government efficiency. There have been several government initiatives to ensure transparency, openness and anti-corruption, for example, "Chile and the Philippines both have developed e-procurement systems that allow members of the public to actively monitor government bidding and contracting processes to prevent corruption in the awarding of contracts and grants" (Anderson, 2009).

The integration of social media tools into government agencies' businesses and services present a new set of challenges and issues that need to be addressed. These include challenges related to privacy, security, accessibility, social inclusion, governance, and information policy (Bertot, Jaeger \& Hansen, 2012). According to "Transparency and Open Government, Memorandum for the Heads of Executive Departments and Agencies", (2009) the government needs to develop strategies and models for how to use these enabling technologies to achieve a transformation of every aspect of government, such as service provision, decision and policy making, administration, governance and democracy. The number of social media users have been increasing significantly worldwide over the last decade. In the second quarter of (2018), Facebook announced that it had over 2.25 billion active users. According to "The average number of tweets per day" (2018) the average number of tweets per day is 58 million, It is also mentioned in the "Instagram Statistics engagement levels" (2018), there are 55 million photos uploaded every day through Instagram. Social media tools can be misused and abused by employees at the workplace. In order to eliminate these kinds of violations. The use of social media applications need to be regulated and monitored by government officials. The researchers (Maamar, et al. 2015) have proposed and develop a system to set some restrictions and rules on social actions (e.g. chat, post, like, tag, comment, etc.) initiated by employees. As an example of restrictions include, time of the social session, number of characters per message and others. The main aims of this research study are to make decision makers, including operation managers, decision makers, social media managers, marketing managers, etc. in government organizations and agencies, aware of the pitfalls and challenges of adopting social media at the workplace, provide decision makers with set of recommendations and best practices on how to benefit from social media at the workplace, and to introduce a theoretical framework to serve as guidance for government agencies to help them successfully integrate social media technologies in its day to day operations and services in order to enhance communication, promote transparency and encourage citizen engagement.

The paper is organized as follows, first section discusses the potential use of social media in general. The subsequent section presents the related work for the main theme of the paper. The last section contains proposed framework that can be applied to government agencies as well as recommendations for social media integration in organizations, and suggestions for future research.

\section{RELATED WORK}

Government organizations need to think of ways to tap into the opportunities offered by social media technologies to help them engage their constituents in regard of the decision-making process. In a study conducted by (Bertot, Jaeger \& Grimes, 2011) to examine the ways in which governments integrate social media and ICTs into e-government to promote transparency, collaboration with the public and ways the public can monitor government performance. The study identified several key initiatives, potential impact and 
challenges facing future e-government public collaboration. "A survey of 1,160 business and IT professionals shows that while $46 \%$ of the organizations increased their investments in social technologies in 2012, only $22 \%$ believed that managers are prepared to incorporate social tools and approaches into their processes" (Vizard, 2012). Today's enterprises must juggle with globalization challenges (local vs. global competition), market volatility (new regulations), stakeholder diversity (customers, suppliers, etc. question to be addressed, could government organizations tap into the social media world.

Social media is playing an important and increasing role in natural disasters and crises as an information disseminator that can be used by disaster relief organizations (Gao, Barbier \& Goolsby, 2011). It was used heavily and effectively in the catastrophic Haiti earthquake which took place on January 12, 2010. After the earth quick, people of Haiti posted numerous text messages and photos from different badly hit areas, via social media platforms, such as twitter, Facebook and Blogs. In just 48 hours, Red cross has received a large funds for donations. A similar situation in Japan caused by the recent tsunami and earthquake made it difficult for people to communicate with each other via the jammed mobile phone networks, instead they used social media networks to keep in touch with the love ones. Another example in November 2018 when the devastating California Camp wildfire that damaged more than 150,000 acres of land in and destroyed nearly 14,000 homes ("Social Media in Government: Benefits, Challenges and How it's Used", 2019). Due to extremely dry weather and shifting winds, the wildfire became a logistical nightmare for first responders and government officials who wanted to maintain public safety. Local government officials turned into social media tools to help get the hundreds of thousands impacted by the fires to get to safety.

Somehow, social media and social responsibility are interrelated. Social responsibility is an ethical framework in which is an entity, be it an organization or individual, has an obligation to act for the benefit of society at large [Wikipedia]. It is a duty every individual must perform to maintain a balance in society. It can also define how individual actions can impact the society at large social responsibility can be passive, by avoiding engaging in socially harmful acts, or positive/active, by performing activities that directly advance social goals ("Social responsibility", 2018). Here are some of the potential use of social media in government entities include:

Citizen Real-time engagement: Social media overcome the barriers of time and place for engagement. It has a potential to engage citizens constantly, it has emerged as a powerful platform for forming an opinion as well as educating citizens about public policies and promoting public events and new initiatives.

Sharing information: Social media has a great potential to spread information to many users within a blink of an eye. People can share your social posts with a single tap/click, and immediately share it with their friends, family and colleagues.

Handling perceptions sentiment sensing: One of the big challenges for government is to avoid negativity or misleading rumors with respect to government services, practices and policies. Government must have a presence on these platforms to encounter and correct such perceptions.

Government organizations need to develop a new business model to specify the technological need for social media applications that seem relevant for sustaining the growth and fall into its mission. In addition, organizations need to craft the necessary procedures and policies that allow an appropriate use of these applications, identifies the relevant metrics (or key performance indicators) that permit to evaluate its effectiveness, efficiencies and ROIs.

\section{RECOMMENDATIONS FOR INTEGRATING SOCIAL MEDIA IN GOVERNMENT ORGANIZATIONS}

This paper addresses how social media technologies could be integrated effectively into government institutions as well as ways of implementing these approaches. Therefore, we offer the following recommendations, each covers different aspects of the integration process.

Viability and ROI Aspect. Government organizations need to develop a new business model to ensure a smooth integration. Without tangible benefits, accurate performance indicators, and proper unstructured content for use, it will be challenging for any government top decision makers to back its social media integration. Government agencies need to make an integration strategy plan and decide the budget how much you can spend to implement their plan. Put their strategy into action, understand your demographics and people are talking about the organization. 
Legal and Ethical Aspect. Governments need to open up a new communication channels to reach out to stakeholders. The integration of social media in government day to day operations pose a new set of challenges on how to achieve a smooth implementation that can be productive and beneficial to the organization with a tangible and acceptable results. In order to have effective social media integration, it should be institutionalized and embedded in the organization structure and operations. Government organizations over the years have adopted different social media strategies and plans that serve their needs and comply with the rules of engagement with the public. The adopted strategy should cover all aspects of social media interaction include the main targeted citizens and their profile to ensue positive user experience, what goals will be achieved through the social media integration, what type of content to share with the public, the collected social data should be analyzed periodically to understand citizens' pressing concerns and issues, assign roles of responsibility for each individual of the social media team, perform a regular re-assessment of the effectiveness of using social media tools, how social media usage has impacted the organization online presence and enhanced citizens' engagement and experience.

Technical Aspect. The organizations need to have a good understanding the different types of available social media technologies in terms of features and functions, platforms, domain, as well as cost and limitations. Set the necessary criteria and performance indicators that will allow selecting the appropriate social media technologies depending on the government organizations' strategic goals and mission. In addition, develop a feasible risk analysis (e.g., what-if) which is able to specify the impact of social media applications on the enterprise operations and reputations.

Operational Aspect. The organization needs to develop all the necessary policies and procedures that permit and regulate an efficient and correct use of the social applications at the workplace. Indicate how, when, and where employees can engage in social media operations. Define the nature of content and material that can be discussed and shared over social media applications. Develop the necessary policies and procedures for reaching out to clients/ respondents over social media platforms. Be prepared for such a situation of "I did not know". Without proper awareness and guidance this could become the default response to actions taken over social media applications.

Management Aspect. The management aspect identifies the relevant metrics (or key performance indicators) that permit to evaluate this efficient use of social media in the government organization. Evaluate how the organization can leverage social media applications through tangible benefits (e.g. key performance indicators). Monitor constantly and periodically the activity levels of the social media applications (e.g., number of active members and number of posted messages) Assess the added value of social media applications on return-on-investment (e.g., number of new customers and increase in sales volume). Harness the available content on social media applications into a content that is suitable for decision makers.

\section{CONCLUSION}

Social media offers a real opportunity for government organizations to enhance their services and open new channels of communication with their constituents to promote participation, transparency and engagement. In order to achieve these objectives, government agencies need to be meticulous and smart about how to integrate and implement these social media tools. Today's economic and political climates pose new challenges to those who make decisions by relying on personal contacts and unstructured information sources such as social networks. Enterprise executives' reliance on social networks raises concerns over drawing the line between professional and social life's. There is a growing interest in how organizations should capitalize on social technologies such as social networks, blogs, and wikis. A social organization is one that strives to open-up new communication channels with stakeholders using such technologies. This paper proposed an architecture and a guiding framework to help integrate social technologies into organization operations. Social government entities need a new business and working model which include: Technology perspective identifies the future Web 2.0 applications that seem relevant for sustaining the enterprise growth and fall into its mission. Organization perspective puts in place the necessary procedures that permit an efficient use of the Web 2.0 applications. Management perspective identifies the relevant metrics (or key performance indicators) that permit to evaluate this efficient use. Government organizations' executives' reliance on social networks raises concerns over drawing the line between professional and social life. 


\section{REFERENCES}

Anderson, T.B. (2009). E-government as an anti-corruption strategy. Information Economics and Policy, Vol. 21, pp. 201-10.

Bertot, C., Jaeger, P., Munson, S., Glaisyer, T. (2010). Engaging the public in open government: The policy and government application of social media technology for government transparency IEEE Computer. 43 (11), pp. 53-59

Bertot, C., Jaeger, P., Grimes, M. (2010). Using ICTs to create a culture of transparency: E-government and social media as openness and anti-corruption tools for societies Government Information Quarterly, 27, pp. 264-271.

Bertot, J., Jaeger, P., Hansen, D. (2012). The impact of polices on government social media usage: Issues, challenges, and recommendations. Government Information Quarterly Volume 29 (1), Pages 30-40.

Bertot, C., Jaeger, P., Grimes, M. (2011). Promoting transparency and accountability through ICTs, social media, and collaborative e-government. April Issue.

Boyd, D.M. and Ellison, N.B. (2007). Social network sites: definition, history, and scholarship. Journal of Computer-Mediated Communication, Vol. 13 No. 1, pp. 210-30.

Gao, H., Barbier, G., Goolsby, R. (2011). Harnessing the Crowdsourcing Power of Social Media for Disaster Relief. CY BER - PHYSICAL - SOCIAL SYSTEMS. Retrieved from www.computer.org/intelligent.

Instagram Statistics engagement levels (2018). Retrieved from http://jennstrends.com/wp-content/uploads/2014/02/2014IG-Stats-Engagement-Levels.jpg.

Maamar, Z., Bur'egio, V., Faci, N., Benslimane, D., Sheng, Z. (2015). Controlling Web 2.0 Applications in the Workplace. The Proceedings of the 19th International IEEE Enterprise Distributed Object Computing Conference (EDOC'2015), Adelaide, Australia.

Mulgan, R. (2007). Truth in government and the politicization of public service advice. Public Administration, Vol. 85, pp. 569-86.

Number-of-monthly-active-facebook-users-worldwid(2018)

Retrieved

from https:/www.statistica.com/statistics/264810/number-of-monthly-active-facebook-users-worldwide.

Shuler, J., Jaeger, P., Bertot, J. (2010). Implications of harmonizing e-government principles and the Federal Depository Library Program (FDLP). Government Information Quarterly, Vol. 27, pp. 9-16.

Social Media in Government: Benefits, Challenges and How it's Used. (2019). Retrieved from https://blog.hootsuite.com/social-media-government/.

Social responsibility. Wikipedia (2018). Retrieved from https://en.wikipedia.org/wiki/Social_responsibility

Porter, J. (2008). Designing for the Social Web: Cross RefView Record in Scopus Google Scholar. New Riders Press, Thousand Oaks, CA.

Reylea, H.C. (2009). Federal freedom of information policy: highlights of recent developments. Government Information Quarterly, Vol. 26, pp. 314-20.

Transparency and Open Government, Memorandum for the Heads of Executive Departments and Agencies (2009). The White House, Retrieved: 21 Jan 2009. http://www.gwu.edu/ nsarchiv/news/20090121/2009 transparency memo.pdf; http://www. whitehouse.gov/the press office/TransparencyandOpenGovernment/.

The average number of tweets per day (2018). Retrieved from http://www.statisticbrain.com/twitter-statistics

Vizard, M. (2012). IBM: Business Processes Need to Get Social in 2013. IT Business Edge, December issue. 